\title{
Changes in Parvalbumin Content and its Isoform Pattern in the Muscle of Red Sea Bream along with Muscle Development
}

\author{
Hikaru Hemmi, ${ }^{\dagger 1, \uparrow 2}$ Michiaki Yamashita, and Fujio Nishioka \\ National Research Institute of Fisheries Science, Fukuura, Kanazawa, \\ Yokohama, Kanagawa 045, Japan
}

(Received August 21, 1996)

\begin{abstract}
Parvalbumin content and its isoform pattern in the muscle of red sea bream Pagrus major were analyzed during the course of development from the larval stage to adult stage. Parvalbumin content in the muscle was found to increase from the larval stage to juvenescence stage, followed by a small decrease until the young stage. Furthermore, its isoform pattern was found to change from the larval stage to adult stage. These results indicate that parvalbumin is closely related with muscle development.
\end{abstract}

Key words: parvalbumin, red sea bream, muscle

Parvalbumin (PV) is a water-soluble, high-affinity $\mathrm{Ca}^{2+}$. binding, and heat-stable protein with a molecular weight of approximately 12,000 . The protein has been detected in many species of vertebrates, but is especially abundant in the white muscle of fishes and amphibians. "Furthermore, muscle of lower vertebrates (fish and amphibian) contains up to five isoparvalbumins whereas higher vertebrates were believed to contain only one protein per species. ${ }^{\text {" }} \mathrm{PV}$ is structurally related to troponin $\mathrm{C}$, myosin light chain and other $\mathrm{Ca}^{2+}$-binding proteins. It has been proposed that PV may facilitate $\mathrm{Ca}^{2+}$ translocation within the sarcoplasm. ${ }^{2)}$ In addition, it was found that the PV content and $\mathrm{Ca}^{2+}$ - and $\mathrm{Mg}^{2+}$ - dissociation rates were correlated with changes in relaxation rate of frog muscle fibers at $0^{\circ} \mathrm{C},{ }^{3)}$ and furthermore, $\mathrm{PV}$ levels in skeletal muscles of mammals were correlated positively with relaxation speed. ${ }^{4)}$

In this study, we found that the PV content and its isoform pattern changes along with the course of muscle development in red sea bream.

\section{Materials and Methods}

\section{Fish}

Red sea bream Pagrus major which were hatched artificially and grown in a floating fish preserve on the sea were collected at three different developmental stages: larval (average body length $9.8 \mathrm{~mm}, 28$-day-old), juvenescence (body length from 12.2 to $49.6 \mathrm{~mm}$, from 39-day-old to 79-day-old) and young (average body length $86.2 \mathrm{~mm}$, 109-day-old) stages. The sample fish were quickly frozen with dry-ice acetone. Five adult fish (average body length $502 \mathrm{~mm}$, two-year-old) were purchased from Nanbu Fish Market, Yokohama. All sample fish were kept at $-40^{\circ} \mathrm{C}$ until use. length, both of the dorsal and ventral muscles including the red muscle were used as specimens, except for two juvenile fish whose dorsal white muscle was used for the assay. In the case of fish over $50 \mathrm{~mm}$ of body length, only the dorsal white muscle was used. The specimens were homogenized with $2 \mathrm{vol}$ of $50 \mathrm{~mm}$ cold phosphate buffer (pH 6.8) for $5 \mathrm{~min}$ at $0^{\circ} \mathrm{C}$ using a non-bubbling homogenizer (Nihon Seiki). The homogenate was centrifuged for 30 min at $2000 \times g$ at $5^{\circ} \mathrm{C}$. The supernatant was collected and heated up to $100^{\circ} \mathrm{C}$ for $30 \mathrm{sec}$ by a microwave oven, and further heated for $2 \mathrm{~min}$ at $100^{\circ} \mathrm{C}$. After being cooled with ice, they were centrifuged for $30 \mathrm{~min}$ at $2000 \times \mathrm{g}$ at $5^{\circ} \mathrm{C}$. The supernatant was collected as a heat-stable protein fraction. The PV content in this fraction was determined using a Protein Assay Kit (Bio-Rad) founded on the Bradford protein assay. ${ }^{5)}$ Bovine serum albumin was used as a standard.

\section{Gel Electrophoresis and Western Blotting}

Non-denaturing polyacrylamide gel electrophoresis (non-denaturing PAGE) was run in Tris-glycine buffer (pH 8.3). ${ }^{6}$ Samples for electrophoresis were mixed with the Tris-glycine buffer containing $15 \%$ sucrose ( $\mathrm{pH} 8.3$ ) and were applied to $9 \%$ gels. After electrophoresis, protein bands were stained by Coomassie Brilliant blue R-250. For immunoblot analysis, PV separated by non-denaturing PAGE using 9\% gel were transferred electrophoretically to a nitrocellulose sheet (Bio-Rad) according to the method of Towbin et al. ${ }^{7)}$ After blocking, the nitrocellulose sheet was treated with the monoclonal antibody of carp PV (clone No. PA-235, Sigma) followed by alkaline phosphate-conjugated anti-mouse IgG (Bio-Rad). The bands of reaction products on the sheet were visualized with 5-bromo-4-chloro-3-indolyl phosphate in combination with nitro blue tetrazolium.

\section{Preparation of Parvalbumin}

In the case of red sea bream below $50 \mathrm{~mm}$ of body

\footnotetext{
†1 Present address: National Food Research Institute, Kannondai, Tsukuba, Ibaraki 305, Japan.

†2 To whom correspondence should be addressed. E-mail: hemmi@nfri.affrc.go.jp.
} 


\section{Results and Discussion}

\section{Identification of Parvalbumin}

To ascertain whether most of the heat-stable proteins is parvalbumin, first we compared the heat-stable protein with the water-soluble protein in the muscle of fish at the adult stage (about $500 \mathrm{~mm}$ body length) in PAGE pattern. The non-denaturing PAGE pattern showed that the watersoluble protein fraction contains many protein components that do not exist in the heat-stable protein fraction (Fig. 1A), however, the western blotting patterns of the heat-stable protein and the water-soluble protein with anti-carp PV monoclonal antibody coincided with each other (Fig. 1B). The western blotting pattern also indicates that the number of parvalbumin isoform present in the muscle is three (PVI, PVII and PVIII) at the adult stage (Fig. 1A). These findings indicate that the heat-stable protein fraction consists of three parvalbumins. The result was also supported by a comparison by gel-filtration chromatography of the heat-stable proteins and the water-soluble proteins of the muscle (data not shown).

\section{Change in the Parvalbumin Content along the Muscle De- velopment}

The total PV content per gram of muscle weight increased from the larval stage to the juvenescence stage, followed by a slight decrease until the young stage (Fig. 2). In the muscle of fish at the adult stage, PV content was estimated to be about 3-4 mg/g of muscle, which was slightly lower than that in the young fish muscle.

Recently, there have been some reports describing that the PV level in skeletal muscles of mammals is correlated positively to the muscle relaxation speed. ${ }^{4,8)}$ In red sea bream also, the marked development of swimming ability and muscle must be related to each other and the juveniles of red sea bream of more than approximately $30 \mathrm{~mm}$ in length change completely from a pelagic to a bottom-dwelling life style. ${ }^{9)}$ The experimental data showed that the PV level rapidly rises at the earlier stage of growth, passes through a peak during the juvenescence stage where the fish is around $30 \mathrm{~mm}$ in length, falls to a constant level, and drops further when the fish has matured. This finding indicates that the PV level in the muscle of red sea bream is related to the muscle development.
(A)

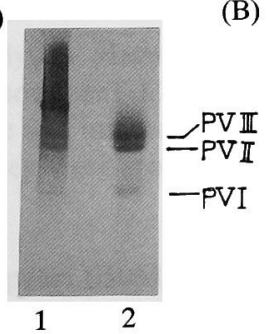

(B)

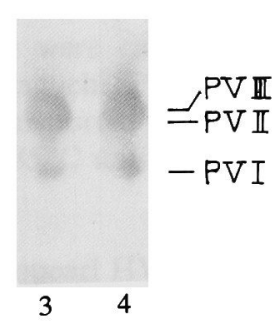

Fig. 1. Non-denaturing PAGE (9\%) patterns (A) and western-blotting patterns with anti-PV antibody (B) of the water-soluble proteins (lanes 1 and 3) and the heat-stable proteins (lanes 2 and 4) in the muscle of red sea bream.

Parvalbumin isoforms are represented by PVI, PVII and PVIII.

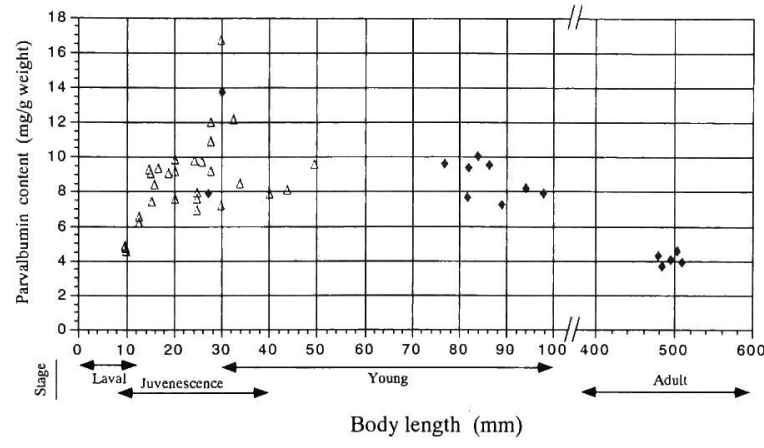

Fig. 2. Change in the content of parvalbumins in the lateral muscles $(\triangle)$ and the skeletal muscle $(\bullet)$ along with muscle development.

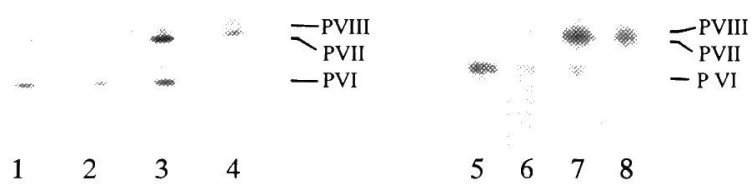

Fig. 3. Non-denaturing PAGE (9\%) patterns (A) and western-blotting patterns (B) of parvalbumins (PVI, PVII and PVIII) in larval fish (lane 1 and 5), juvenile fish (lane 2 and 6), young fish (lane 3 and 7) and adult fish (lane 4 and 8 ).

\section{Change in Parvalbumin Isoform Pattern}

Non-denaturing PAGE patterns (Fig. 3A) and western blotting patterns (Fig. 3B) of parvalbumin in the muscle of fish at each developmental stage are shown in Fig. 3. Both the non-denaturing PAGE and western blotting patterns changed with the change of developmental stage of the fish. In the non-denaturing PAGE and western blotting patterns for the larval stage fish and juvenescent stage fish, PVI and PVII were observed but PVIII was not observed. In the patterns for the larval fish, PVI was stronger than PVII in the staining intensity. In the case of the young fish, three isoforms (PVI, PVII and PVIII) were observed, but the staining intensity of PVIII was weaker than those of PVI and PVII. Furthermore, in the case of the adult fish, the staining intensity of PVI was much weaker than those of PVII and PVIII. From these results, it can be concluded that the parvalbumin isoform composition changes along with the muscle development.

Previous research in higher vertebrates has shown that changes in isoforms of various muscular proteins, such as myosin and troponins, are regulated by muscle development. ${ }^{10)}$ Although there have been few reports mentioning that isoforms of muscular protein change along with the muscle development in fish, our finding suggests that drastic biochemical changes may occur at the juvenescence stage where the fish is around $30 \mathrm{~mm}$ in length. The isoform patterns of various muscular proteins may change at this stage in response to muscle development.

Furthermore, since red sea bream change their habitat 
from the surface layer to bottom layer in the sea as they grow during this stage, ${ }^{\text {9) }}$ the change in parvalbumin isoforms may be due to the environmental change, as pointed out in studies on the temperature adaptation of carp myosin isoforms. ${ }^{11,12}$

Acknowledgments We thank Dr. S. Konagaya, SEAFDEC, Singapore, and Dr. H.Nakano, National Research Institute of Fisheries Science, for their kind advice and encouragement.

\section{References}

1) Ch. Gerday: Soluble calcium-binding proteins from fish and invertebrates muscle. Molec. Physiol., 2, 63-87 (1982).

2) C. W. Heizmann and M. W. Berchtold: Expression of parvalbumin and other $\mathrm{Ca}^{2+}$-binding proteins in normal and tumor cells: a topical review. Cell Calcium, 8, 1-41 (1987).

3) T.-T. Hou, J. D. Johnson, and J. A. Rall: Parvalbumin content and calcium ion and magnesium ion dissociation rates correlated with changes in relaxation rate of frog muscle fibers. $J$. Physiol., 441, 285-304 (1991).

4) C. W. Heizmann, M. W. Berchtold, and A. M. Rowlerson: Correlation of parvalbumin concentration with relaxation speed in mammalian muscles. Proc. Natl. Acad. Sci. USA, 79, 7243-7247 (1982).

5) M. M. Bradford: A rapid and sensitive method for the quantitation of microgram quantities of protein utilizing the principle of protein-dye binding. Anal. Biochem., 72, 248-254 (1976).

6) B. J. Davis: Disc electrophoresis II. Methods and application to human serum proteins. Ann. N.Y. Acad. Sci., 121, 404-427 (1964).

7) H. Towbin, T. Staehelin, and J. Gordon: Electrophoretic transfer of proteins from olyacrylamide gels to nitrocellulose sheets: procedure and some applications. Proc. Natl. Acad. Sci. USA, 76, 43504354 (1979).

8) M. Munter, L. Kaser, J. Weber, and M. W. Berchtold: Increase of skeletal muscle relaxation speed by direct injection of parvalbumin cDNA. Proc. Natl. Acad. Sci. USA, 92, 6504-6508 (1995).

9) O. Fukuhara: Functional morphology and behavior of early life stages of red sea bream. Nippon Suisan Gakkaishi, 51, 731-743 (1985).

10) M. L. Pearson and H. F. Epstein: Muscle Development. Molecular and Cellular Control., Cold Spring Harbor Laboratory, Cold Spring Harbor, 1982, pp. 1-581.

11) X.-F. Guo, M. Nakaya, and S. Watabe: Myosin subfragment-1 isoforms having different heavy chain structures from fast skeletal muscle of thermally acclimated carp. J. Biochem., 116, 728-735 (1994).

12) S. Watabe, H. Imai, T. Uozumi, I. Hirono, and T. Aoki: Temperature acclimation induces light meromyosin isoforms with different primary structures in carp fast skeletal muscle. Biochem. Biophys. Res. Commun., 208, 118-125 (1995). 